\title{
Pattern of symptoms and signs of primary intracranial tumours in children and young adults: a record linkage study.
}

Thomas P C Chu PhD (1)

Anjali Shah PhD (2)

David Walker FRCPCH (3)

Michel P Coleman FFPH (1)

(1) Cancer Survival Group, Department of Non-communicable Disease Epidemiology, London School of Hygiene and Tropical Medicine, Keppel Street, London WC1E 7HT.

(2) Nuffield Department of Orthopaedics, Rheumatology and Musculoskeletal Sciences, University of Oxford, Headington, Oxford OX3 7LD.

(3) Children's Brain Tumour Research Centre, University of Nottingham, Queen's Medical Centre, Nottingham NG7 2UH.

Correspondence: Thomas P C Chu; e-mail: thomas.chu@Ishtm.ac.uk

MeSH keywords: brain neoplasms, signs and symptoms, early diagnosis, symptom assessment.

Published in Archives of Disease in Childhood (2015).

http://dx.doi.org/10.1136/archdischild-2014-307578

PMID: 26044137 


\section{Abstract}

\section{Objective}

To describe the age pattern and temporal evolution of symptoms and signs of intracranial tumours in children and young adults before diagnosis.

\section{Design and setting}

A record linkage study using population-based data from the National Cancer Registry, linked to Clinical Practice Research Datalink (CPRD) and Hospital Episode Statistics (HES).

\section{Patient cohort}

Patients aged 0-24 years when diagnosed with a primary intracranial tumour between 1989 and 2006 in England.

\section{Methods}

Linked records of relevant symptoms and signs in primary care and hospitals were extracted from CPRD (1989-2006, 181 patients) and HES (1997-2006, 3,959 patients). Temporal and agespecific changes in presentation rates before diagnosis of an intracranial tumour, for each of eight symptom groups, were estimated in generalised additive models.

\section{Results}

All symptoms presented with increasing frequency until eventual diagnosis. The frequency of presentation of raised intracranial pressure to hospitals rose rapidly to 36.4 per 100 person-months (95\% Cl: 34.6-38.4) in the final month before diagnosis in the entire cohort. Clinical features in primary care were less specific: the main features were visual disturbance (rate: 0.49 per 100 person-months; $95 \% \mathrm{Cl}$ : $0.33-0.72)$ in $0-4$ year-olds, headache in $5-11$ year-olds $(0.64 ; 0.47-$ 0.88), 12-18 year-olds $(1.59 ; 1.21-2.08)$ and $19-24$ year-olds $(2.44 ; 1.71-3.49)$. The predominant features at hospital admission were those of raised intracranial pressure: between 1.17 per 100 person-months (95\% Cl: 1.08-1.26) in 0-4 year-olds and $0.77(0.67-0.88)$ in 19-24 year-olds. 


\section{Conclusions}

Non-localising symptoms and signs were more than twice as common as focal neurological signs.

An intracranial tumour should be considered in patients with relevant symptoms that do not resolve or that progress rapidly. 


\section{Introduction}

Over 500 patients aged 0-24 years are diagnosed with an intracranial tumour in England annually.[1] Intracranial tumours took longer to diagnose than many other childhood cancers.[2-7] There has been considerable interest in reducing the time interval between symptom onset and diagnosis to improve survival and quality of life, and has led to the production of guidelines [8] and introduction of a campaign ("HeadSmart - be brain tumour aware", www.headsmart.org.uk) to reduce the symptomatic interval of intracranial tumours before their diagnosis in children and teenagers.

Recent studies on early diagnosis have largely focused on the predictive power of symptoms and signs for all cancers.[9-15] Intracranial tumours are distinctive in their diversity of clinical features, and thus warrant an in-depth investigation into presentation patterns in relation to their natural history and the diagnostic process. Recent advances in record linkage methods [16-18] have created such an opportunity for studying the history of presentation in primary care and National Health Service (NHS) hospitals. We described the sequence of symptoms and signs in both primary and secondary care leading up to the eventual diagnosis of an intracranial tumour, using linked medical records from Clinical Practice Research Datalink (CPRD) and Hospital Episode Statistics (HES) in a population-based cohort with histologically verified tumours.

\section{Data source}

The Office for National Statistics (ONS) has been collating information on tumour pathology and patient vital status in England to maintain the National Cancer Registry since 1971. Data quality is audited regularly on ascertainment, timeliness, completeness, accuracy and validity.[19 20] Ascertainment of central nervous system tumours is over 98\%.[21] Fewer than $1 \%$ of registrations are of poor quality.[20] Agreement between pathology reports and registry data within broad diagnostic group was $93 \%$, with the date of diagnosis within six weeks of each other in $94 \%$ of records.[22]

The Clinical Practice Research Datalink (formerly General Practice Research Database) is a 
database of person-specific longitudinal records of consultations and diagnoses in primary care. Over 600 practices, covering $5-10 \%$ of the UK population, have been contributing data to CPRD since 1989.[23] Hospital Episode Statistics contains records of in-patient admissions in English NHS hospitals, including data on admission, diagnoses, treatment and discharge of each in-patient stay.[24] CPRD commissioned the linkage of their records externally, and Thames Cancer Registry and Northern and Yorkshire Cancer Registry and Information Service carried out the linkage of HES records to tumour registrations by matching on NHS number, sex, date of birth and postcode.[25-27]

\section{Methods}

\section{Patient cohort}

We identified from the National Cancer Registry patients aged 0-24 years when diagnosed with a primary intracranial tumour between 1989 and 2006 as the cohort with primary care data, and between 1997 and 2006 as a second cohort with hospital data. We have included patients presenting up to age 24 years since they are often managed in specialist teenage cancer units. We defined intracranial tumours as those coded to a relevant location (supratentorial compartment, midline, cerebellum, brainstem, ventricular system, meninges, cranial nerves or other) in the ninth or tenth revision of the International Classification of Diseases (ICD),[28 29] with a compatible morphological code from the third edition of the International Classification of Childhood Cancer (diagnostic groups III, IX.b.2, IX.d.8 and X.a).[30]

Tumour registrations were excluded with the same criteria as for National Statistics: records with invalid dates, unknown sex, unknown vital status, secondary or metastatic tumour, patients not resident in England and Wales, or records that failed ONS validity checks. Records of synchronous tumours (with an identical date of diagnosis relating to the same person) or multiple primary tumours (with same tumour location and person identifier) were also excluded.[31] Such records could have come from patients with a genetic predisposition such as neurofibromatosis or tuberous sclerosis and were likely to be under surveillance, and expected to have a diagnostic pathway 
outside the scope of this study.

We obtained the linked CPRD and HES records, and extracted a subset of consultations or inpatient stays with one or more presenting features that fell into one of eight pre-specified groups of tumour-related symptoms and signs.

\section{Presenting features}

Symptoms, signs and diagnoses at each consultation are recorded as Read codes in CPRD [32] and as ICD-10 codes in HES. Each hospital "episode" may contain up to 14 "diagnoses" or presenting features, with the main feature recorded as the "primary diagnosis". We searched the full code list to identify over 800 codes representing features that could be related to an intracranial tumour. These were grouped into eight categories: headache; other features of raised intracranial pressure (e.g. nausea, vomiting); convulsions; visual disturbance (e.g. features of cranial nerves II, III, IV or VI dysfunction); focal neurological deficit; growth or endocrine disorders; behavioural (e.g. cognitive) problems and general or non-specific symptoms (e.g. delayed milestone, irritability). We assumed a consultation or hospital stay to be tumour-related if the "primary diagnosis" in HES or any of the symptoms in CPRD came from one of the above groups.

Each hospital episode can be further classified as "non-emergency" or "emergency" by its method of admission. In an emergency admission, patients were admitted via the Accident and Emergency department, directly by the general practitioner, via the bed bureau, urgently from an outpatient clinic or by urgent transfer from another hospital.

The observation time in HES for each patient began on the later of the date of birth or the start of HES data and ended with the earlier of the date of death or the end of HES data. The observation time in CPRD began on the date of registration with the primary care practice, and ended with the earliest of the date of death, transfer-out date (if a patient had moved to a practice not included in CPRD) or last collection date (when data were last submitted). We divided the observation time for each individual into monthly intervals before and after the date of diagnosis in the National Cancer Registry, which is defined under international standards.[33 34] 
The presentation rate is the number of hospital episodes (from HES) or primary care consultations (from CPRD) divided by the observation time, that is, the length of time during which an individual could present to primary care or hospitals and thus have a record in CPRD or HES. We reported presentation rates using the age at which patients presented, to mirror the normal developmental stages and clinical practice in paediatrics, for the following groups: $0-4,5-11,12-18$ and $19-24$ years to examine the pattern in age-specific symptoms and signs before the diagnosis of an intracranial tumour. We also reported presentation rates for $0-1,1-3,3-6,6-12$ and over 12 months from the date of definitive diagnosis to investigate the evolution of symptoms and signs before and after the diagnosis of an intracranial tumour. Rates and confidence intervals were estimated in generalised linear models with the number of presentations as the response, and the logarithm of the length of observation time as the offset.

The presentation rates showed considerable month-to-month fluctuations. To demonstrate the underlying trend, we used generalised additive models with locally weighted regression (LOESS) to smooth monthly presentation rates in the time domain.[5 35] In a LOESS smoother, a lowdegree polynomial regression is fitted for each observation using observations that are close to the one of interest. This is repeated until the mean response of every observation has been estimated. A weighted least squares algorithm is used in the process, with the weight values determined by a tri-cube function: greater weights are assigned to observations nearer to the month at which the presentation rate was estimated.[35 36] The distribution of weights reflects the view that events close to the index presentation are more likely to be related, and are thus assigned greater weights, and events distant from the index presentation are less likely to be related, so carry less weight.

Analyses were implemented using functions from the 'gam' package [37] and in the statistical language R.[38] Computationally intensive calculations were carried out on the High Performance Computing cluster at the London School of Hygiene and Tropical Medicine.

\section{Results}

We identified 9,799 patients diagnosed with an intracranial tumour between 1989 and 2006 from 
the National Cancer Registry, after excluding 279 patients with ineligible records. Death-certificateonly registrations, the information for the basis of registration came solely from the death certificate, comprised $0.6 \%$ of the records we analysed.

We extracted 3,787 primary care records (CPRD) that were linked to 181 (1.85\%) of these 9,799 individuals. Because hospital records had only been linked to tumours registered from 1997, we extracted 60,351 HES records linked to 3,959 (78.2\%) of the 5,061 individuals diagnosed since. Linkage of HES was proportionally more successful in patients aged $0-4$ years, patients with a cerebellar or brainstem tumour, and patients with a tumour outside the sellar region (all $P<0.001$ ) (Table 1). The number of patients with linked CPRD records is close to our expectation from its population coverage and the proportion of practices that consented to linkage (about half). The proportion of tumour records that were successfully linked varied by tumour morphology $(P=0.03)$, but not for sex $(P=0.4)$, age $(P=0.9)$, tumour location $(P=0.3)$ or behaviour $(P=0.2)$.

\section{The overall pattern}

Patients with an intracranial tumour presented with one or more tumour-related symptoms before diagnosis in 6,973 hospital admissions (of which 3,640 via an emergency route), at an overall presentation rate of 3.3 per 100 person-months (1.7 per 100 person-months for emergency admissions). The presentation rate increased from 1.3 per 100 person-months (95\% Cl: $1.1-1.4)$ in the period 6-12 months before diagnosis to 6.4 per 100 person-months (5.8-7.0) in the period 1-3 months before diagnosis (Table 2). The steepest increase occurred in the final month before diagnosis, when the rate rose to 134.0 (130.4-137.6). Similarly, the emergency presentation rate increased from 0.6 per 100 person-months (95\% Cl: 0.5-0.7) to $73.0(70.4-75.7)$ between 12 months and the final month before diagnosis (Figure 1). The proportion of emergency presentations rose from $45 \% 6-12$ months to $55 \%$ in the final month.

Presentations in primary care were more frequent than in hospitals: 926 consultations for a tumourrelated symptom took place before diagnosis at an overall rate of 6.0 per 100 person-months. The frequency of consultations rose from 8.4 per 100 person-months $(95 \% \mathrm{Cl}: 6.8-10.5)$ at 6-12 months to 148.9 (131.9-168.1) in the final month (Table 2 and Figure 2). Patients were seen in 
primary care over four times as often as in hospitals up to the final month before the tumour was diagnosed. The time at which the presentation rate began to rise steeply was also earlier in primary care (3-6 months before diagnosis) than in hospital (0-1 month).

Presentation rates fell rapidly within the first three months after diagnosis, with a steeper fall occurring in primary care visits (Figure 1 and 2). The rate of emergency hospital visits, which were not subject to normal follow-up schedule, also fell rapidly after diagnosis.

\section{Primary care consultations}

Headache was the most common presenting symptom in patients older than 5 years with presentation rates increasing with age ( 0.64 per 100 person-months in $5-11$ year-olds to 2.44 in 19-24 year-olds), but was one of the uncommon symptoms in 0-4 year-olds $(0.10 ; 95 \% \mathrm{Cl}$ : $0.04-$ 0.24). In this age group, other features of raised intracranial pressure (e.g. vomiting, increased head circumference) were far more common $(0.42 ; 0.28-0.65)$ (Table 3A).

Convulsions were unusual in patients under 18 years (between 0.20 and 0.30 per 100 personmonths) but were common in patients over 18 years $(2.36 ; 1.64-3.40)$. Visual disturbance was the most common symptom group in $0-4$ year-olds $(0.49 ; 0.33-0.72)$, the second most common symptom group $(0.35 ; 0.23-0.53)$ after headache in $5-11$ year-olds and the third most common $(0.48 ; 0.29-0.78)$ after headache and general non-specific symptoms in 12-18 year-olds.

Patients began presenting to their general practitioners from about 24 months before the diagnosis of an intracranial tumour (see online supplementary material): mainly with headache or convulsions, and sometimes together with signs of cranial nerve II, III, IV or VI dysfunction or with growth or endocrine disorders (Table 3B). Consultation rates for focal neurological deficits, nonspecific features and behavioural problems began to rise 6-12 months before the diagnosis of an intracranial tumour. Features in every symptom group presented with increasing frequency, but those of raised intracranial pressure (e.g. nausea, vomiting, papilloedema, increased head circumference) were uncommon until the final month before diagnosis (rate $=10.3$ per 100 personmonths, 95\% Cl: 6.47-16.3). Localising symptoms and signs such as visual disturbance and focal neurological deficits were far less prominent than non-specific symptoms. 


\section{Hospital presentations}

Although headache was unusual in $0-4$ year-olds $(0.07$ per 100 person-months, $95 \% \mathrm{Cl}$ : $0.05-$ 0.10), it was one of the common symptoms in older patients (Table $4 \mathrm{~A})$. Other features of raised intracranial pressure (e.g. nausea, vomiting, papilloedema) were prominent in every age group (between 0.77 and 1.17 per 100 person-months), particularly in younger patients. Other common presentations included convulsions (between 0.28 and 0.61 ) and focal neurological deficits (between 0.20 and 0.33).

Clinical features from every symptom group occurred with increasing frequency with time in every age group (Table 4B). Convulsions began to present from 12 months before an intracranial tumour was diagnosed (see online supplementary material). Features in other symptom groups were seen only from 3-6 months, with those of raised intracranial pressure seldom occurred until 1-3 months before diagnosis.

Localising features such as focal neurological deficits and visual disturbance were not commonly detected before the brain tumour diagnosis: focal neurological deficits $(0.54$ per 100 personmonths, $95 \% \mathrm{Cl}: 0.40-0.73)$ were only one-third as frequent as raised intracranial pressure (1.45; $1.20-1.74)$ or convulsions $(1.46 ; 1.21-1.75)$ in the $1-3$ months before diagnosis. Features of raised intracranial pressure (36.4 per 100 person-months, $95 \% \mathrm{Cl}: 34.6-38.4)$ were five times as common as focal neurological deficits $(7.78 ; 6.96-8.71)$ or visual disturbance $(6.49 ; 5.74-7.34)$ in the final month before diagnosis.

A large proportion of admissions with headaches (82-96\%) came through an emergency route (Table 4B). In contrast, a smaller proportion of presentations with other features of raised intracranial pressure (60-69\%), convulsions (46-76\%) or focal neurological features (52-74\%) was admitted urgently.

\section{Discussion}

Every symptom presented with increasing frequency until the intracranial tumour was eventually diagnosed. The most common clinical features presented to hospitals were those of raised 
intracranial pressure and convulsions. Headache and focal neurological deficits were not prominent, especially early in the natural history of intracranial tumours. This pattern was similar in all age groups, except among 0-4 year-olds, in whom headache was rarely reported. Other features of raised intracranial pressure (such as vomiting, increased head circumference) were detected more frequently in children under 4 years.[12] Our findings are consistent with earlier studies in which headache, vomiting and non-localising symptoms were generally found to be the more common features in the entire pre-diagnosis period,[[9 1013$]$ but we have also examined when in the time course before the brain tumour diagnosis those symptoms were common.

The primary care presentation rate for many symptoms and signs began to increase earlier than in hospital admissions, and with a more variable pattern: headache was, by far, the most common feature except in 0-4 year-olds, in whom features of raised intracranial pressure were more common. This is compatible with the development of language and cognitive functions in children and the capacity of the skull to accommodate an increase in intracranial pressure before the sutures fuse. Visual disturbances were among the more common and specific features and their presence, especially in 0-4 year-olds, should prompt consideration of an intracranial tumour as a possible cause. Very young or uncooperative children in whom an ophthalmic examination cannot be performed adequately should therefore be referred for specialist assessment.[8]

Rising presentation rates in both primary and secondary care in the last few months before diagnosis of an intracranial tumour implies the diagnostic pathway in paediatric patients does not fit the model for adult patients, in which diagnostic delay is divided into discrete components of primary care and secondary care.[39-43] Healthcare professionals seeing children should therefore be aware of the pattern in the temporal development of clinical features that may require further investigations: in patients with repeat attendances with similar symptoms or a recent history of rapid symptom progression causing parental concern.[8]

Other non-localising features (e.g. symptoms of raised intracranial pressure, general non-specific symptoms such as lethargy, fatigue, drowsiness, appetite loss, irritable, failure to thrive, etc.) were far more common than localising features, especially early in the natural history of intracranial tumours - a finding that is consistent with previous studies.[2 46791013 44] We also found that 
changes in the proportion of emergency admissions before a diagnosis of an intracranial tumour were comparable with the pattern observed in adults.[45]

\section{Strengths and limitations}

Progression of brain tumour symptoms and signs has been extensively studied,[4 5 7 9-11 13-15 46] culminating in the development of guidelines for clinical assessment.[8 4748 ] Earlier studies have often been limited to examining this in a community-based or hospital-based cohort, usually in a single institution. Advances in record linkage methodology have enabled study of symptom progression and healthcare service use in a population-based cohort with a histologically verified diagnosis. Other advantages include greater accuracy of the data on tumour diagnosis and avoidance of recall and selection bias, a problem that affects data collected after diagnosis in patient interviews or manual review of medical notes. In using the date of diagnosis from the National Cancer Registry (derived under international standards[33 34]) to divide each patient's history into pre-diagnosis and post-diagnosis periods, we have ensured consistency in the timing of emergence of clinical features when comparing results from primary care and hospital data. We have also been able to demonstrate (rather than to assume) a fall in the presentation rate, both in primary care and in hospitals, for every symptom group after the intracranial tumour diagnosis. This highlights the importance of a timely diagnosis in planning appropriate treatment.

Although the primary care records were only available for a small number of patients, this is still one of the largest population-based cohort of children and young adults with a histologically verified brain tumour. Potential explanations for the lack of linked records include differences in geographical overlap with the National Cancer Registry, quality of matching variables, linkage algorithm efficiency, and each patient's probability of healthcare service use. For example, patients with a tumour in the sellar region were more likely to have presented with endocrinopathies that were less likely to necessitate in-patient stays for their management. This would imply their medical history is less likely to be captured in HES. We do not have data on symptoms that occurred before the first clinical contact unless they were reported to general practitioners. Such data may only be obtained from interviewing patients or their parents, which would be susceptible 
to bias from differential recall or participation. We are, however, confident that the data are representative of patients who presented to their general practitioners or admitted as in-patients in NHS hospitals, and the symptom data accurately reflect each clinician's interpretation of the importance of presenting features.

We have analysed the presentation rate, not simply the number of presentations, in order to avoid the bias associated with unequal observation time between patients. A fixed length of prediagnosis interval has been used in some studies, but that may have introduced bias in estimation of the number of visits in patients with slow-growing tumours or of symptom interval in younger children.

We have assumed homogeneity in the effect of tumour location and morphology when using generalised linear models to analyse presentation rates.[49-51] Variability associated with tumour location and morphology will be examined elsewhere.

\section{Conclusion and implications}

Among children and young adults with an intracranial tumour, non-localising features such as lethargy, drowsiness, failure to thrive, parental concern, headache and features of raised intracranial pressure were far more common than specific features such as focal neurological deficits throughout the pre-diagnosis period. In all age groups, cranial nerve II, III, IV or VI dysfunction was also common in primary care. Many of these symptoms occurred with increasing frequency with tumour progression. Features of raised intracranial pressure become the most common group of presenting features in the final month before diagnosis.

The pattern of symptom development was complex, so the predictive power of an isolated feature or combination of features is likely to be weak. The possibility of an intracranial tumour as a differential diagnosis should be considered in patients presenting with symptoms that fail to settle or progress rapidly, rather than relying on the presence or absence of specific symptoms or signs. 


\section{Acknowledgements}

We thank Children with Cancer UK for funding this work through their Jane Davidson and Paul O'Gorman Scholarship (TPCC). We thank colleagues at the Cancer Survival Group, London School of Hygiene and Tropical Medicine for their guidance on data management and statistical analysis.

\section{Contributors}

TPCC searched the literature, designed the study, carried out data management and statistical analysis, interpreted the findings and drafted the manuscript. AS helped with literature search, study design and contributed to interpretation of findings. DW helped with literature search. MPC helped with literature search, secured data access, advised on study design, data analysis and interpretation of findings. All authors contributed to revision of the manuscript.

\section{Competing interests}

TPCC's doctoral fellowship was funded by Children with Cancer UK. DW and TPCC are funded by The Brain Tumour Charity to evaluate the effects of HeadSmart, a public campaign to raise awareness of brain tumour symptoms. DW receives funding from the Health Foundation and is a member of the Children with Cancer UK scientific advisory panel. MPC and AS do not have any conflict of interest.

\section{Ethics approval}

The Research Ethics Committee at the London School of Hygiene and Tropical Medicine approved this study (reference number 5566). 


\section{What is already known on this topic}

1. The clinical features of intracranial tumours are diverse and often non-specific.

2. Suspicion of an intracranial tumour is often only triggered when a child presented with localising features such as focal neurological deficits.

3. The time to diagnosis for intracranial tumours was longer than for many other childhood cancers. The predictive power of symptoms and signs is poor.

\section{What this study adds}

1. In primary care, the main features were those of visual disturbance in children aged 0-4 years, and headache in older children and young adults.

2. Features of raised intracranial pressure were the most common group of symptoms presented in hospitals. They emerged 3-6 months before diagnosis.

3. The proportion of emergency presentations to hospitals rose steadily from $35 \%$ over 12 months before diagnosis to $55 \%$ by the time of diagnosis. 


\section{References}

1. Stiller C. Childhood Cancer in Britain: Incidence, survival, mortality. Oxford, UK: Oxford University Press, 2007.

2. Dobrovoljac M, Hengartner H, Boltshauser E, et al. Delay in the diagnosis of paediatric brain tumours. Eur $J$ Pediatr 2002;161(12):663-7.

3. Dang-Tan T, Franco EL. Diagnosis delays in childhood cancer: a review. Cancer 2007;110(4):703-13.

4. Reulecke BC, Erker CG, Fiedler BJ, et al. Brain tumors in children: initial symptoms and their influence on the time span between symptom onset and diagnosis. J Child Neurol 2008;23(2):178-83.

5. Ansell $P$, Johnston T, Simpson J, et al. Brain tumor signs and symptoms: analysis of primary health care records from the UKCCS. Pediatrics 2010;125(1):112-9.

6. Brasme JF, Chalumeau M, Doz F, et al. Interval between onset of symptoms and diagnosis of medulloblastoma in children: distribution and determinants in a population-based study. Eur $\mathrm{J}$ Pediatr 2012;171(1):25-32.

7. Wilne $\mathrm{S}$, Collier J, Kennedy $\mathrm{C}$, et al. Progression from first symptom to diagnosis in childhood brain tumours. Eur J Pediatr 2012;171(1):87-93.

8. Wilne S, Koller K, Collier J, et al. The diagnosis of brain tumours in children: a guideline to assist healthcare professionals in the assessment of children who may have a brain tumour. Arch Dis Child 2010;95(7):534-9.

9. Wilne SH, Ferris RC, Nathwani A, et al. The presenting features of brain tumours: a review of 200 cases. Arch Dis Child 2006;91(6):502-6.

10. Coserria Sanchez JF, Garrido Ocana Al, Quiroga Cantero E, et al. [Presenting signs and symptoms of central nervous system tumors according to age]. An Pediatr (Barc) 2007;66(2):115-20.

11. Hamilton W, Kernick D. Clinical features of primary brain tumours: a case-control study using electronic primary care records. Br J Gen Pract 2007;57(542):695-9.

12. Wilne S, Collier J, Kennedy C, et al. Presentation of childhood CNS tumours: a systematic review and meta-analysis. Lancet Oncol 2007;8(8):685-95.

13. Vazquez Roman S, Martinez Anton A, Llorente Otones L, et al. [Initial signs and symptoms of brain tumors in children]. Neurologia 2008;23(4):215-9.

14. Dommett RM, Redaniel MT, Stevens MC, et al. Features of childhood cancer in primary care: a population-based nested case-control study. Br J Cancer 2012;106(5):982-7.

15. Dommett RM, Redaniel MT, Stevens MC, et al. Features of cancer in teenagers and young adults in primary care: a population-based nested case-control study. Br J Cancer 2013;108(11):2329-33.

16. Fellegi I, Sunter A. A Theory for Record Linkage. Journal of the American Statistical Association 1969;64(328):1183-210.

17. Gill L. Methods for Automatic Record Matching and Linkage and their Use in National Statistics. Norwich, UK: Her Majesty's Stationery Office, 2001.

18. Statistics New Zealand. Data Integration Manual. Wellington, New Zealand: Statistics New Zealand, 2006.

19. Office for National Statistics. Cancer statistics registrations: Registrations of cancer diagnosed in 2006, England. Newport, UK: Office for National Statistics, 2008.

20. Office for National Statistics. Cancer statistics registrations: Registrations of cancer diagnosed in 2007, England. Newport, UK: Office for National Statistics, 2010.

21. Kroll ME, Murphy MF, Carpenter LM, et al. Childhood cancer registration in Britain: capture-recapture estimates of completeness of ascertainment. Br J Cancer 2011;104(7):1227-33.

22. Dickinson HO, Salotti JA, Birch PJ, et al. How complete and accurate are cancer registrations notified by the National Health Service Central Register for England and Wales? J Epidemiol Community Health 2001;55(6):414-22.

23. GPRD. The General Practice Research Database. London, UK: GPRD, 2011.

24. Health and Social Care Information Centre. The processing cycle and HES data quality. Leeds, UK: Health and Social Care Information Centre, 2014.

25. Hanchett N. ONS to HES Linkage Release 1: Core Documentation. London, UK: Thames Cancer Registry, King's College London, 2008.

26. Boggon R. Linkage of National Cancer Registry data to the General Practice Research Database (GPRD) for cancer survival analysis: data set specification (letter to Prof M Coleman), 2010.

27. Thames Cancer Registry. National Cancer Data Repository - 1990 to 2008: Matching Registry Records to Hospital Episodes Version 1.2. London, UK: Thames Cancer Registry, King's College London, 2011.

28. World Health Organization. Manual of the international statistical classification of diseases, injuries, and causes of death. Geneva, Switzerland: World Health Organization, 1977.

29. World Health Organization. International statistical classification of diseases and related health problems. 
Geneva, Switzerland: World Health Organization, 1992.

30. Steliarova-Foucher E, Stiller C, Lacour B, et al. International Classification of Childhood Cancer, third edition. Cancer 2005;103(7):1457-67.

31. Coleman MP, Babb P, Damiecki P, et al. Cancer survival trends in England and Wales, 1971-1995: deprivation and NHS region. London, UK: The Stationery Office, 1999.

32. General Practice Research Database. GPRD Medical Browser, version 1.3.1. London, UK: Medicines and Healthcare products Regulatory Agency, 2010.

33. International Agency for Research on Cancer, International Association of Cancer Registries. Cancer Registration: Principles and Methods. Lyon, France: International Agency for Research on Cancer, 1991.

34. United Kingdom Association of Cancer Registries. Po/99/03 Definition of Diagnosis Date: United Kingdom Association of Cancer Registries, 2011.

35. Chambers J, Hastie T. Statistical Models in S. London, UK: Chapman \& Hall, 1993.

36. Cleveland W. Robust Locally Weighted Regression and Smoothing Scatterplots. Journal of the American Statistical Association 1979;74(368):829-36.

37. Hastie T. gam: Generalized Additive Models, 2011.

38. R Core Team. R: A Language and Environment for Statistical Computing. Vienna, Austria, 2011.

39. Olesen F, Hansen RP, Vedsted P. Delay in diagnosis: the experience in Denmark. Br J Cancer 2009;101 Suppl 2:S5-8.

40. Richards MA. The National Awareness and Early Diagnosis Initiative in England: assembling the evidence. Br J Cancer 2009;101 Suppl 2:S1-4.

41. Nekhlyudov L, Latosinsky $S$. The interface of primary and oncology specialty care: from symptoms to diagnosis. J Natl Cancer Inst Monogr 2010;2010(40):11-7.

42. Weller D, Vedsted P, Rubin G, et al. The Aarhus statement: improving design and reporting of studies on early cancer diagnosis. Br J Cancer 2012;106(7):1262-7.

43. Neal RD. Do diagnostic delays in cancer matter? Br J Cancer 2009;101 Suppl 2:S9-S12.

44. Edgeworth J, Bullock P, Bailey A, et al. Why are brain tumours still being missed? Arch Dis Child 1996;74(2):148-51.

45. Elliss-Brookes L, McPhail S, Ives A, et al. Routes to diagnosis for cancer - determining the patient journey using multiple routine data sets. Br J Cancer 2012;107(8):1220-6.

46. Ahrensberg JM, Fenger-Gron M, Vedsted $P$. Use of primary care during the year before childhood cancer diagnosis: a nationwide population-based matched comparative study. PLoS One 2013;8(3):e59098.

47. Larner AJ. Referral guidelines for suspected central nervous system or brain tumours. J Neurol Neurosurg Psychiatry 2006;77(12):1305-6.

48. Kernick DP, Ahmed F, Bahra A, et al. Imaging patients with suspected brain tumour: guidance for primary care. Br J Gen Pract 2008;58(557):880-5.

49. Agresti A. Categorical Data Analysis. New Jersey, USA: John Wiley \& Sons, 2002.

50. Venables WN, Ripley BD. Modern Applied Statistics with S. New York, USA: Springer, 2002.

51. Maindonald J, Braun J. Data Analysis and Graphics Using $R$ - an Example-Based Approach. Cambridge, UK: Cambridge University Press, 2010. 


\section{Figures}

\section{Figure 1}

Pattern of hospital presentations in children and young adults with an intracranial tumour before and after diagnosis (time $=0$ at brain tumour diagnosis): England, 1997-2006.

Black line: change in frequency of all hospital presentations (black dots) after locally weighted regression (LOESS) smoothing. Red line: change in frequency of emergency presentations (red dots) after LOESS smoothing.

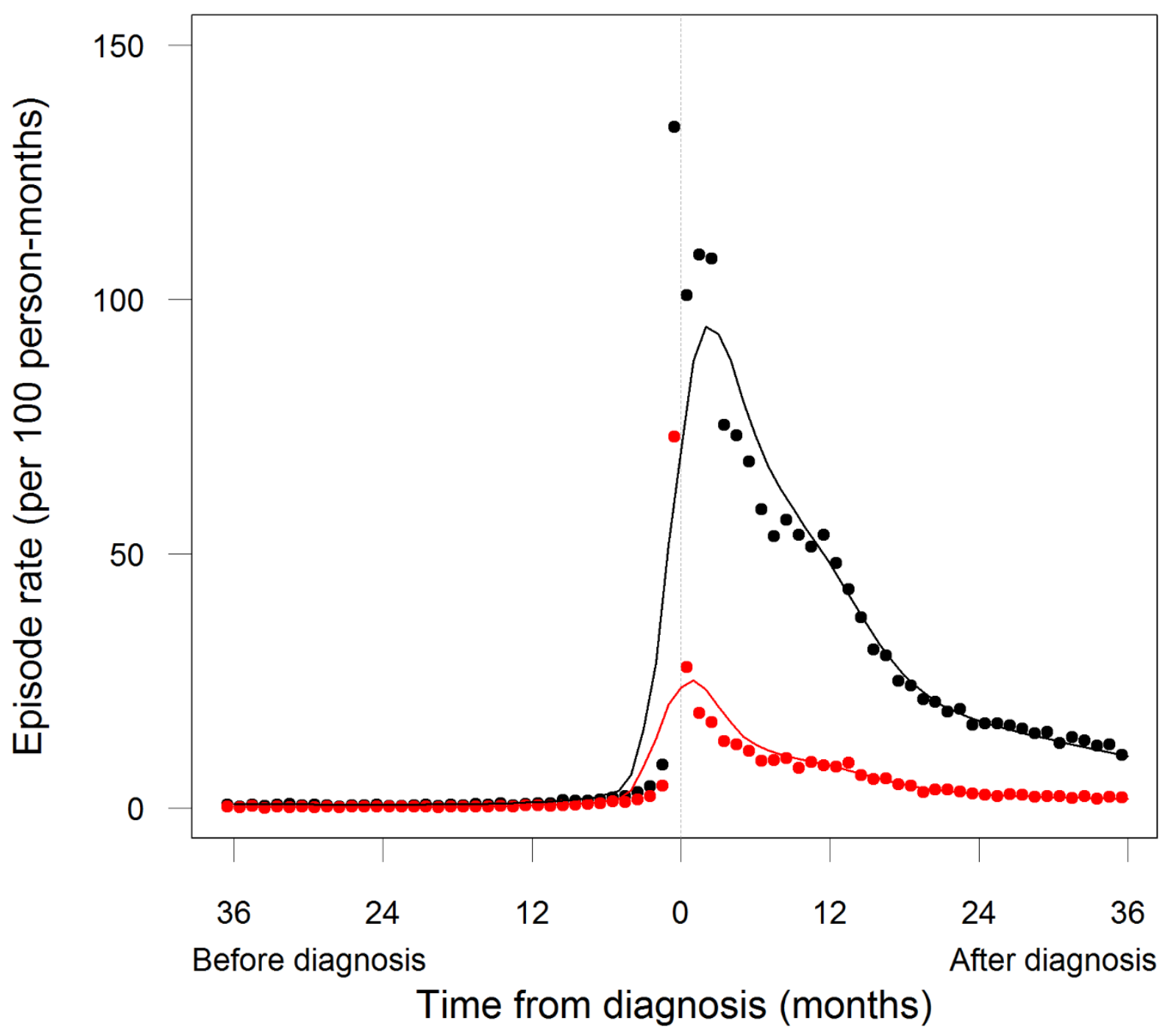




\section{Figure 2}

Pattern of primary care presentations in children and young adults with an intracranial tumour before and after diagnosis (time $=0$ at brain tumour diagnosis): England, 1989-2006.

Solid line: change in frequency of primary care presentations (grey dots) after locally weighted regression smoothing.

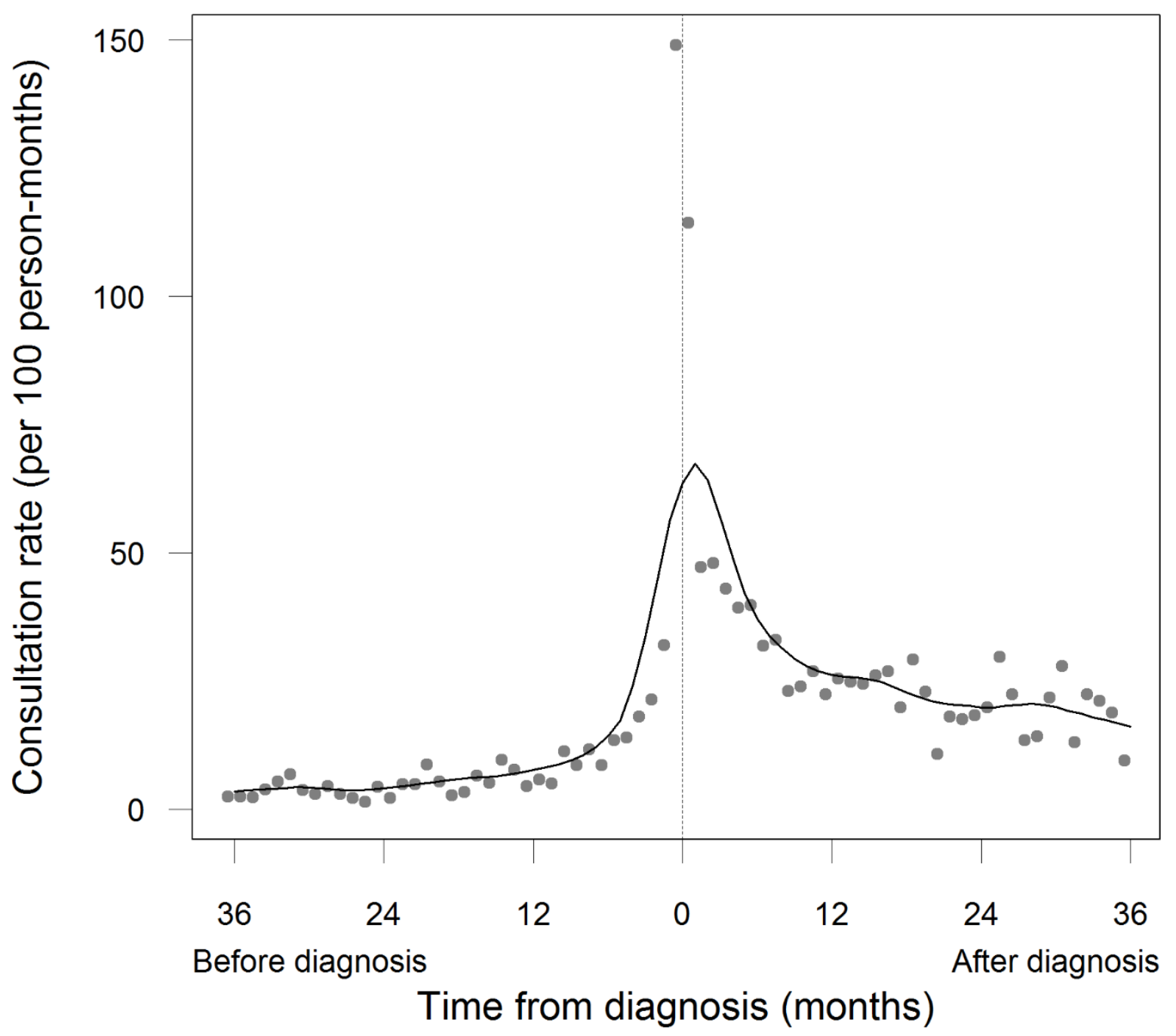


Table 1: Distribution of demographical characteristics in patients from the National Cancer Registry with and without linked HES or CPRD records.

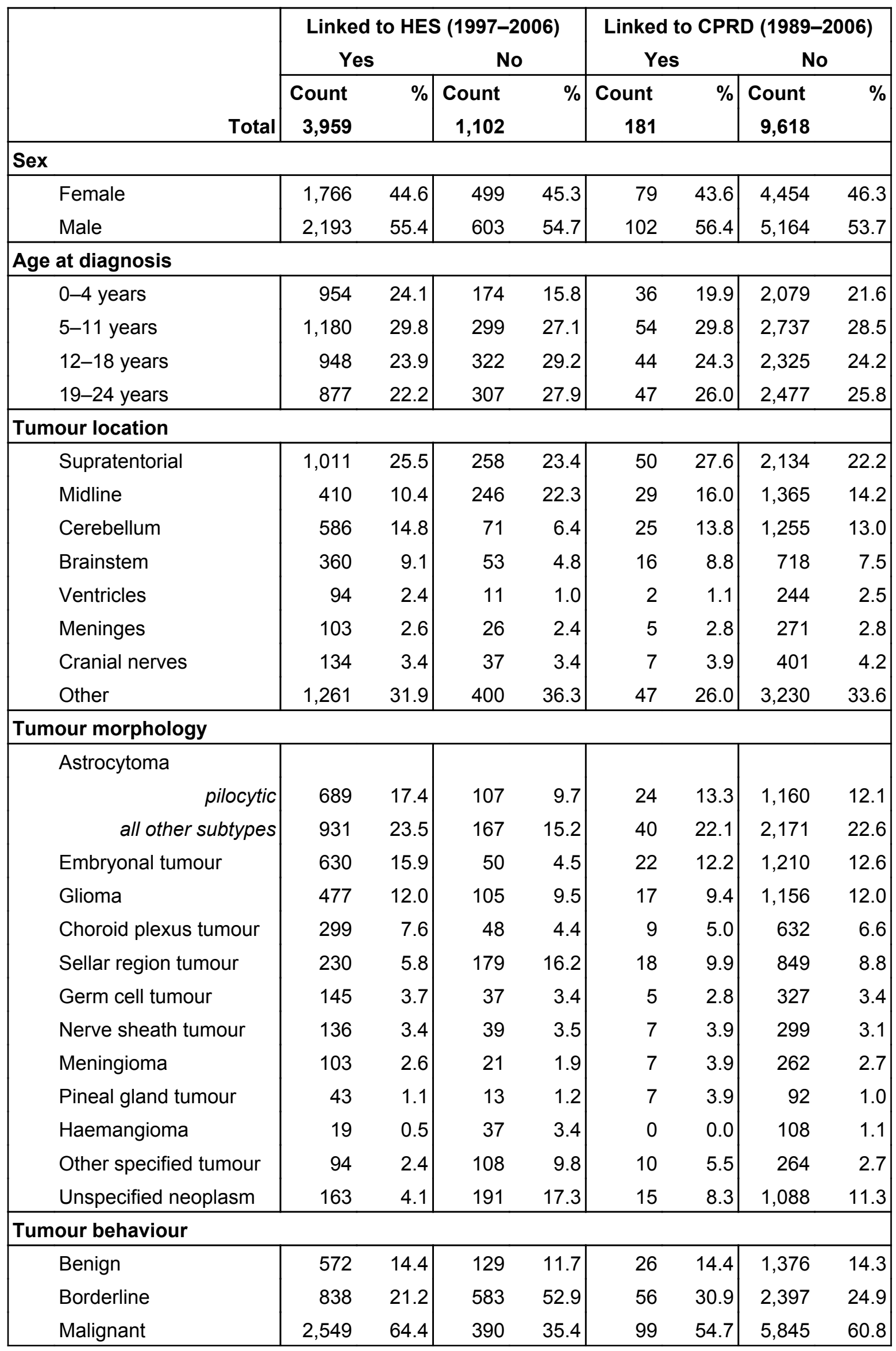

CPRD $=$ Clinical Practice Research Datalink, HES $=$ Hospital Episode Statistics. 


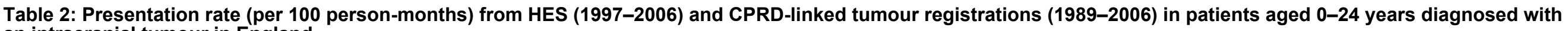
an intracranial tumour in England.

\begin{tabular}{|c|c|c|c|c|c|c|c|c|c|c|c|c|}
\hline \multirow[b]{3}{*}{$\begin{array}{l}\text { Time from diagnosis } \\
\text { (months) }\end{array}$} & \multicolumn{8}{|c|}{ Hospital presentations } & \multirow{2}{*}{\multicolumn{4}{|c|}{ Primary care presentations }} \\
\hline & \multicolumn{4}{|c|}{ All admissions } & \multicolumn{4}{|c|}{ Emergency only } & & & & \\
\hline & $\begin{array}{l}\text { Observation time } \\
\text { (person-months) }\end{array}$ & Count & Rate & $95 \% \mathrm{Cl}$ & Count & Rate & $95 \% \mathrm{Cl}$ & $\% *$ & $\begin{array}{l}\text { Observation time } \\
\text { (person-months) }\end{array}$ & Count & Rate & $95 \% \mathrm{Cl}$ \\
\hline \multicolumn{13}{|l|}{ Before diagnosis } \\
\hline $12+$ months & $164,643.2$ & 635 & 0.4 & $0.4-0.4$ & 224 & 0.1 & $0.1-0.2$ & 35.3 & $13,560.7$ & 417 & 3.1 & $2.8-3.4$ \\
\hline $6-12$ & $21,787.0$ & 276 & 1.3 & $1.1-1.4$ & 125 & 0.6 & $0.5-0.7$ & 45.3 & 972.1 & 82 & 8.4 & $6.8-10.5$ \\
\hline $1-3(a)$ & $7,812.3$ & 498 & 6.4 & $5.8-7.0$ & 260 & 3.3 & $2.9-3.8$ & 52.2 & 340.8 & 91 & 26.7 & $21.7-32.8$ \\
\hline $0-1$ month (b) & $3,943.6$ & 5,283 & 134.0 & $130.4-137.6$ & 2,880 & 73.0 & $70.4-75.7$ & 54.5 & 175.3 & 261 & 148.9 & $131.9-168.1$ \\
\hline \multicolumn{13}{|l|}{ After diagnosis } \\
\hline $0-1$ month & $3,864.6$ & 3,897 & 100.8 & $97.7-104.1$ & 1,067 & 27.6 & $26.0-29.3$ & 27.4 & 175.0 & 200 & 114.3 & $99.5-131.3$ \\
\hline $1-3$ & $7,569.9$ & 8,209 & 108.4 & $106.1-110.8$ & 1,344 & 17.8 & $16.8-18.7$ & 16.4 & 334.3 & 159 & 47.6 & $40.7-55.6$ \\
\hline $3-6$ & $11,074.1$ & 8,002 & 72.3 & $70.7-73.9$ & 1,360 & 12.3 & $11.6-13.0$ & 17.0 & 482.3 & 196 & 40.6 & $35.3-46.7$ \\
\hline $12+$ months & $161,455.1$ & 21,858 & 13.5 & $13.4-13.7$ & 3,949 & 2.4 & $2.4-2.5$ & 18.1 & $11,643.2$ & 2,062 & 17.7 & $17.0-18.5$ \\
\hline
\end{tabular}

(a) This interval lasts from 3 months before diagnosis to the day before 1 month before diagnosis.

(b) This interval lasts from 1 month before diagnosis to the date of diagnosis (inclusive).

* Proportion of hospital episodes that were admitted via an emergency route.

$\mathrm{CPRD}=$ Clinical Practice Research Datalink, HES $=$ Hospital Episode Statistics. 


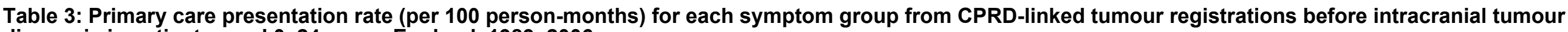
diagnosis in patients aged 0-24 years, England, 1989-2006.

A. By age at presentation:

\begin{tabular}{|c|c|c|c|c|c|c|c|c|c|c|c|c|}
\hline \multirow{2}{*}{$\begin{array}{l}\text { Age at presentation } \\
\text { Length of observation } \\
\text { (person-months) } \\
\text { Symptom group }\end{array}$} & \multicolumn{3}{|c|}{$\begin{array}{c}\text { 0-4 years } \\
4,945.8\end{array}$} & \multicolumn{3}{|c|}{$\begin{array}{c}\text { 5-11 years } \\
6,062.1\end{array}$} & \multicolumn{3}{|c|}{$\begin{array}{c}\text { 12-18 years } \\
3,342.0\end{array}$} & \multicolumn{3}{|c|}{$\begin{array}{c}\text { 19-24 years } \\
1,228.5\end{array}$} \\
\hline & Count & Rate & $95 \% \mathrm{CI}$ & Count & Rate & $95 \% \mathrm{Cl}$ & Count & Rate & $95 \% \mathrm{Cl}$ & Count & Rate & $95 \% \mathrm{Cl}$ \\
\hline Headache & 5 & 0.10 & $0.04-0.24$ & 39 & 0.64 & $0.47-0.88$ & 53 & 1.59 & $1.21-2.08$ & 30 & 2.44 & $1.71-3.49$ \\
\hline Raised ICP & 21 & 0.42 & $0.28-0.65$ & 11 & 0.18 & $0.10-0.33$ & 9 & 0.27 & $0.14-0.52$ & 6 & 0.49 & $0.22-1.09$ \\
\hline Convulsions & 10 & 0.20 & $0.11-0.38$ & 17 & 0.28 & $0.17-0.45$ & 10 & 0.30 & $0.16-0.56$ & 29 & 2.36 & $1.64-3.40$ \\
\hline Visual disturbance & 24 & 0.49 & $0.33-0.72$ & 21 & 0.35 & $0.23-0.53$ & 16 & 0.48 & $0.29-0.78$ & 8 & 0.65 & $0.33-1.30$ \\
\hline Focal deficits & 14 & 0.28 & $0.17-0.48$ & 13 & 0.21 & $0.12-0.37$ & 11 & 0.33 & $0.18-0.59$ & 7 & 0.57 & $0.27-1.20$ \\
\hline Growth or endocrine & 5 & 0.10 & $0.04-0.24$ & 10 & 0.16 & $0.09-0.31$ & 10 & 0.30 & $0.16-0.56$ & 8 & 0.65 & $0.33-1.30$ \\
\hline Behavioural & 21 & 0.42 & $0.28-0.65$ & 19 & 0.31 & $0.20-0.49$ & 3 & 0.09 & $0.03-0.28$ & 0 & 0.00 & not estimated \\
\hline General & 19 & 0.38 & $0.25-0.60$ & 22 & 0.36 & $0.24-0.55$ & 22 & 0.66 & $0.43-1.00$ & 20 & 1.63 & $1.05-2.52$ \\
\hline
\end{tabular}

B. By time from diagnosis:

\begin{tabular}{|c|c|c|c|c|c|c|c|c|c|c|c|c|}
\hline \multirow{2}{*}{$\begin{array}{l}\text { Time from diagnosis } \\
\text { Symptom group }\end{array}$} & \multicolumn{3}{|c|}{ 6-12 months before } & \multicolumn{3}{|c|}{ 3-6 months before } & \multicolumn{3}{|c|}{ 1-3 months before } & \multicolumn{3}{|c|}{ 0-1 months before } \\
\hline & Count & Rate & $95 \% \mathrm{Cl}$ & Count & Rate & $95 \% \mathrm{Cl}$ & Count & Rate & $95 \% \mathrm{Cl}$ & Count & Rate & $95 \% \mathrm{Cl}$ \\
\hline Headache & 16 & 1.65 & $1.01-2.69$ & 9 & 1.81 & $0.94-3.48$ & 22 & 6.46 & $4.25-9.81$ & 49 & 27.96 & $21.13-36.99$ \\
\hline Raised ICP & 1 & 0.10 & $0.01-0.73$ & 3 & 0.60 & $0.19-1.87$ & 3 & 0.88 & $0.28-2.73$ & 18 & 10.27 & $6.47-16.30$ \\
\hline Convulsions & 6 & 0.62 & $0.28-1.37$ & 19 & 3.82 & $2.44-5.99$ & 10 & 2.93 & $1.58-5.45$ & 7 & 3.99 & $1.90-8.38$ \\
\hline Visual disturbance & 9 & 0.93 & $0.48-1.78$ & 9 & 1.81 & $0.94-3.48$ & 8 & 2.35 & $1.17-4.69$ & 15 & 8.56 & $5.16-14.20$ \\
\hline Growth or endocrine & 7 & 0.72 & $0.34-1.51$ & 3 & 0.60 & $0.19-1.87$ & 2 & 0.59 & $0.15-2.35$ & 4 & 2.28 & $0.86-6.08$ \\
\hline Behavioural & 4 & 0.41 & $0.15-1.10$ & 4 & 0.80 & $0.30-2.14$ & 1 & 0.29 & $0.04-2.08$ & 5 & 2.85 & $1.19-6.85$ \\
\hline General & 5 & 0.51 & $0.21-1.24$ & 8 & 1.61 & $0.80-3.22$ & 9 & 2.64 & $1.37-5.08$ & 24 & 13.69 & $9.18-20.43$ \\
\hline
\end{tabular}

$\mathrm{CPRD}=$ Clinical Practice Research Datalink, ICP $=$ intracranial pressure. 


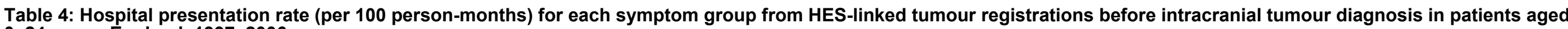
0-24 years, England, 1997-2006.

\begin{tabular}{|c|c|c|c|c|c|c|c|c|c|c|c|c|c|c|c|c|}
\hline \multirow{3}{*}{$\begin{array}{l}\text { Age at presentation } \\
\text { Length of observation } \\
\text { (person-months) } \\
\text { Symptom group }\end{array}$} & \multirow{2}{*}{\multicolumn{4}{|c|}{$\begin{array}{c}0-4 \text { years } \\
55,655.9\end{array}$}} & \multirow{2}{*}{\multicolumn{4}{|c|}{$\begin{array}{c}\text { 5-11 years } \\
70,115.3\end{array}$}} & \multirow{2}{*}{\multicolumn{4}{|c|}{$\begin{array}{c}12-18 \text { years } \\
58,313.0\end{array}$}} & \multirow{2}{*}{\multicolumn{4}{|c|}{$\begin{array}{c}19-24 \text { years } \\
26,435.0\end{array}$}} \\
\hline & & & & & & & & & & & & & & & & \\
\hline & Count & Rate & $95 \% \mathrm{Cl}$ & $\%$ & Count & Rate & $95 \% \mathrm{Cl}$ & $\%$ & Count & Rate & $95 \% \mathrm{Cl}$ & $\%$ & Count & Rate & $95 \% \mathrm{Cl}$ & $\%$ \\
\hline Headache & 41 & 0.07 & $0.05-0.10$ & 83 & 220 & 0.31 & $0.27-0.36$ & 90 & 178 & 0.31 & $0.26-0.35$ & 87 & 79 & 0.30 & $0.24-0.37$ & 86 \\
\hline Raised ICP & 650 & 1.17 & $1.08-1.26$ & 62 & 710 & 1.01 & $0.94-1.09$ & 67 & 449 & 0.77 & $0.70-0.84$ & 64 & 203 & 0.77 & $0.67-0.88$ & 66 \\
\hline Convulsions & 244 & 0.44 & $0.39-0.50$ & 64 & 198 & 0.28 & $0.25-0.32$ & 53 & 333 & 0.57 & $0.51-0.64$ & 52 & 162 & 0.61 & $0.53-0.71$ & 59 \\
\hline Visual disturbance & 103 & 0.19 & $0.15-0.22$ & 37 & 148 & 0.21 & $0.18-0.25$ & 57 & 126 & 0.22 & $0.18-0.26$ & 65 & 54 & 0.20 & $0.16-0.27$ & 54 \\
\hline Focal deficits & 186 & 0.33 & $0.29-0.39$ & 54 & 145 & 0.21 & $0.18-0.24$ & 66 & 135 & 0.23 & $0.20-0.27$ & 47 & 54 & 0.20 & $0.16-0.27$ & 59 \\
\hline Growth or endocrine & 31 & 0.06 & $0.04-0.08$ & 39 & 164 & 0.23 & $0.20-0.27$ & 19 & 75 & 0.13 & $0.10-0.16$ & 25 & 75 & 0.28 & $0.23-0.36$ & 25 \\
\hline Behavioural & 26 & 0.05 & $0.03-0.07$ & 31 & 35 & 0.05 & $0.04-0.07$ & 51 & 29 & 0.05 & $0.03-0.07$ & 62 & 11 & 0.04 & $0.02-0.08$ & 73 \\
\hline General & 131 & 0.24 & $0.20-0.28$ & 60 & 66 & 0.09 & $0.07-0.12$ & 59 & 45 & 0.08 & $0.06-0.10$ & 58 & 14 & 0.05 & $0.03-0.09$ & 86 \\
\hline
\end{tabular}

\section{B. By time from diagnosis:}

\begin{tabular}{|c|c|c|c|c|c|c|c|c|c|c|c|c|c|c|c|c|}
\hline \multirow{2}{*}{$\begin{array}{l}\text { Time from diagnosis } \\
\text { Symptom group }\end{array}$} & \multicolumn{4}{|c|}{ 6-12 months before } & \multicolumn{4}{|c|}{ 3-6 months before } & \multicolumn{4}{|c|}{ 1-3 months before } & \multicolumn{4}{|c|}{ 0-1 months before } \\
\hline & Count & Rate & $95 \% \mathrm{Cl}$ & $\%$ & Count & Rate & $95 \% \mathrm{Cl}$ & $\%$ & Count & Rate & $95 \% \mathrm{CI}$ & $\%$ & Count & Rate & $95 \% \mathrm{Cl}$ & $\%$ \\
\hline Headache & 27 & 0.12 & $0.08-0.18$ & 96 & 28 & 0.24 & $0.17-0.35$ & 89 & 51 & 0.65 & $0.50-0.86$ & 82 & 338 & 8.57 & $7.70-9.53$ & 91 \\
\hline Convulsions & 101 & 0.46 & $0.38-0.56$ & 66 & 105 & 0.92 & $0.76-1.11$ & 70 & 114 & 1.46 & $1.21-1.75$ & 76 & 402 & 10.19 & $9.24-11.24$ & 46 \\
\hline Visual disturbance & 13 & 0.06 & $0.03-0.10$ & 54 & 12 & 0.10 & $0.06-0.18$ & 25 & 33 & 0.42 & $0.30-0.59$ & 45 & 256 & 6.49 & $5.74-7.34$ & 66 \\
\hline Focal deficits & 17 & 0.08 & $0.05-0.13$ & 65 & 27 & 0.24 & $0.16-0.34$ & 74 & 42 & 0.54 & $0.40-0.73$ & 52 & 307 & 7.78 & $6.96-8.71$ & 63 \\
\hline Behavioural & 6 & 0.03 & $0.01-0.06$ & 17 & 9 & 0.08 & $0.04-0.15$ & 56 & 6 & 0.08 & $0.03-0.17$ & 67 & 50 & 1.27 & $0.96-1.67$ & 58 \\
\hline General & 11 & 0.05 & $0.03-0.09$ & 64 & 18 & 0.16 & $0.10-0.25$ & 67 & 25 & 0.32 & $0.22-0.47$ & 48 & 134 & 3.40 & $2.87-4.02$ & 74 \\
\hline
\end{tabular}

Percentages refer to the proportion of hospital episodes that were admitted via an emergency route.

HES $=$ Hospital Episode Statistics, ICP = intracranial pressure . 
Chu TPC, Shah A, Walker D, Coleman MP. Pattern of symptoms and signs of primary intracranial tumours in children and young adults: a record linkage study. Arch Dis Child 2015.

http://dx.doi.org/10.1136/archdischild-2014-307578

\section{Online supplementary material}

- Graphs on the top row illustrate changes in primary care presentations. Those on the bottom row illustrate changes in hospital presentations.

- Primary care presentations:

$\circ$ grey dotted line $=$ observed rates

- black solid line $=$ predicted rates after LOESS smoothing

- Hospital presentations:

- grey line $=$ observed rates of all admissions

- black line $=$ observed rates of emergency admissions only

- blue line $=$ predicted rates of all admissions after LOESS smoothing

○ red lines $=$ predicted rates of emergency admissions after LOESS smoothing

- A common scale was used for the $x$-axes, but we did not use an identical scale for the $y$-axes. We did this to emphasize temporal changes in the presentation rates within each symptom group. 
Chu TPC, Shah A, Walker D, Coleman MP. Pattern of symptoms and signs of primary intracranial tumours in children and young adults: a record linkage study. Arch Dis Child 2015.

Primary care:
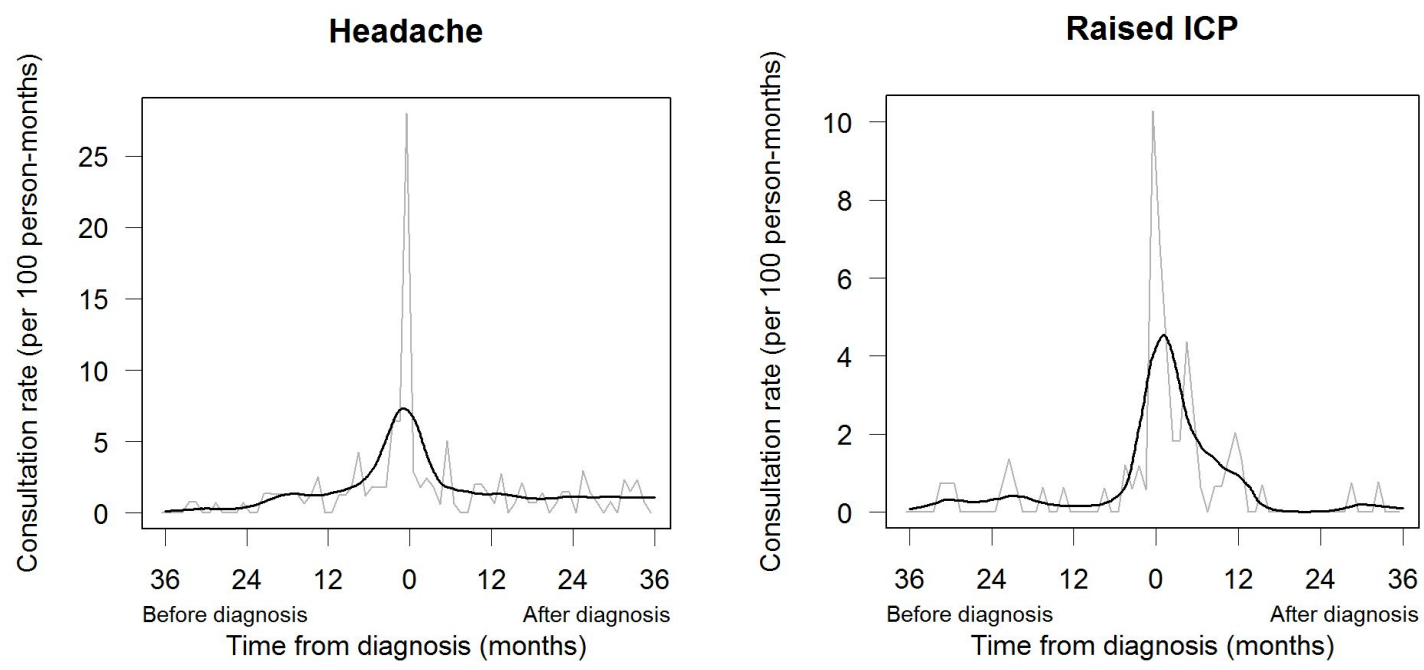

Secondary care:

Headache

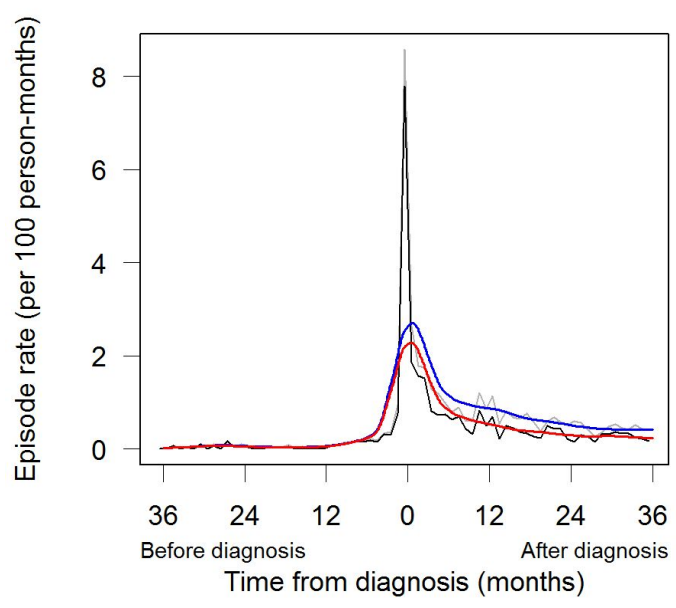

Raised ICP

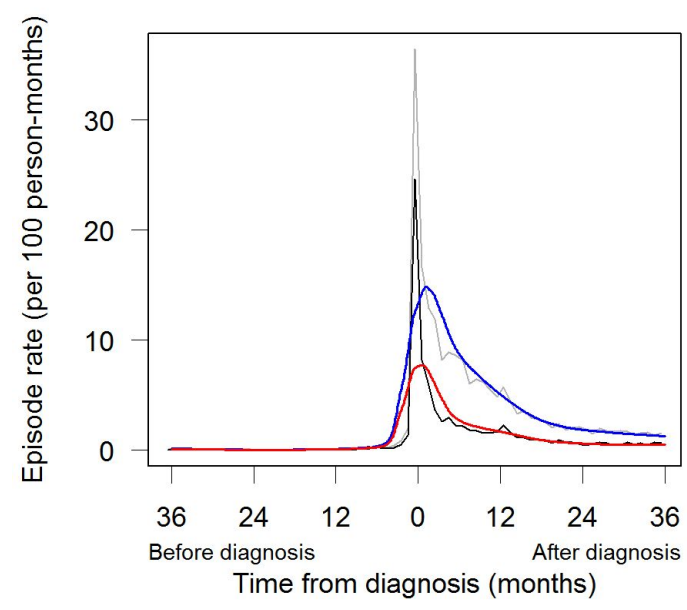

- The frequency of primary care consultations for headache began to increase 24 months before the diagnosis of an intracranial tumour. The frequency of hospital admissions for headache did not increase until six months before diagnosis. The red and blue lines are very close because a high proportion of hospital episodes was admitted as an emergency.

- The frequency of presentations with features of raised intracranial pressure (other than headache) did not begin to increase until about six months before brain tumour diagnosis in both primary and secondary care, implying that the tumour was growing undetected and could be giving rise to complications in the last six months. 
Chu TPC, Shah A, Walker D, Coleman MP. Pattern of symptoms and signs of primary intracranial tumours in children and young adults: a record linkage study. Arch Dis Child 2015.

http://dx.doi.org/10.1136/archdischild-2014-307578

Primary care:
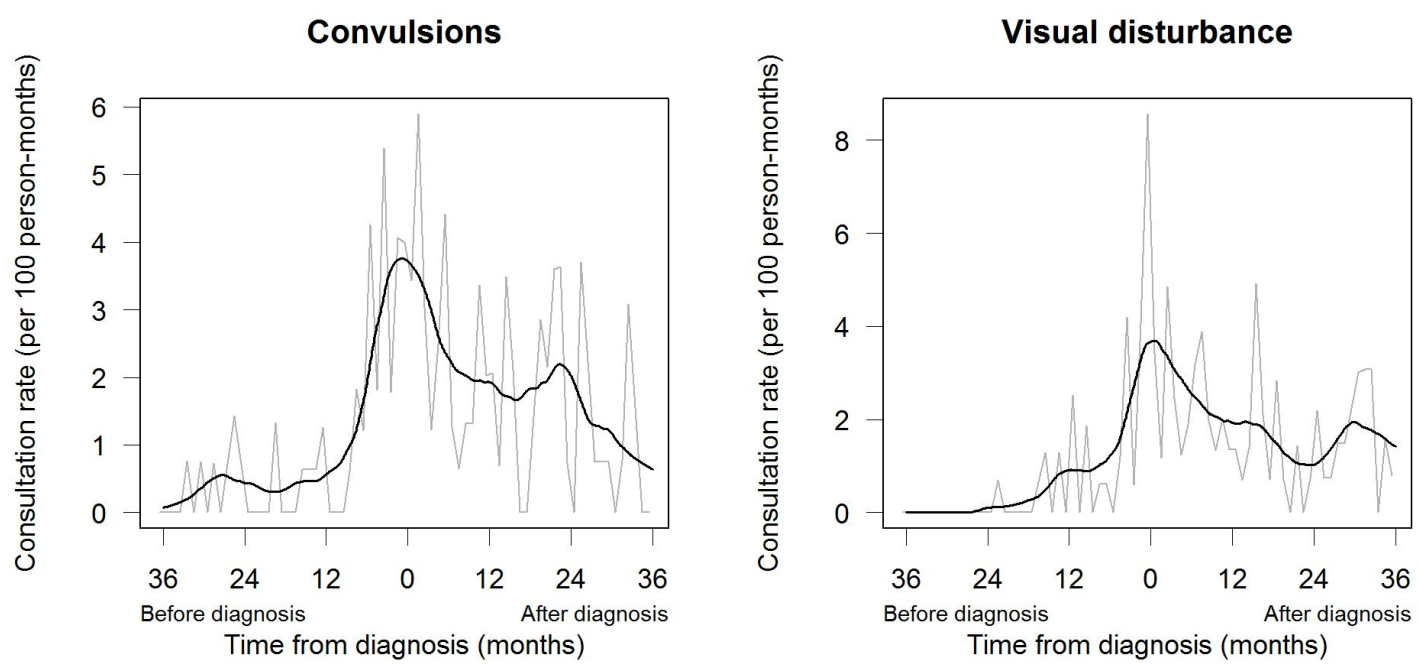

\section{Secondary care:}

\section{Convulsions}

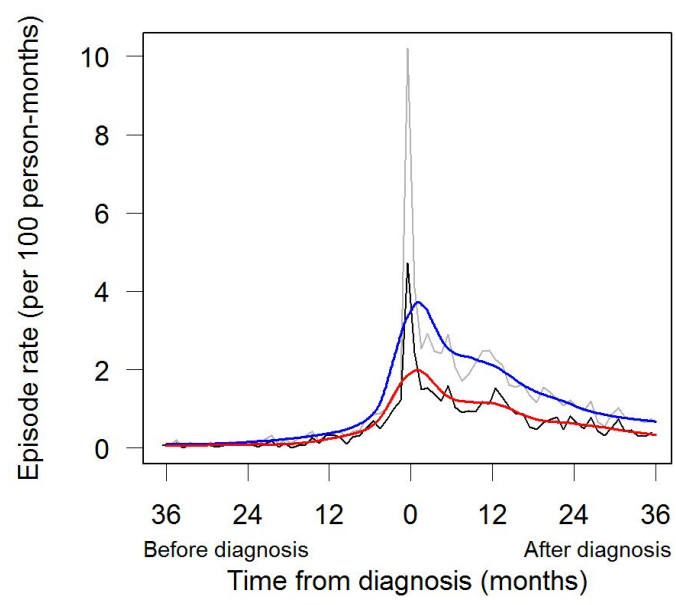

Visual disturbance

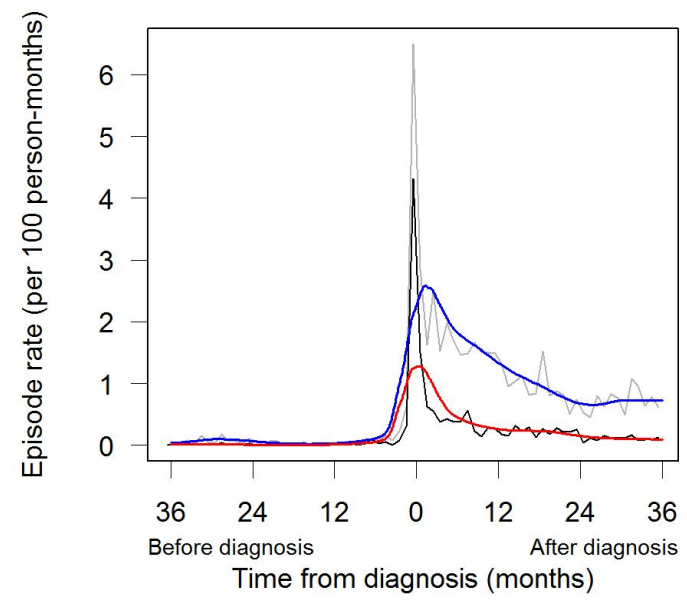

- Convulsions and visual disturbance were not common in primary care. Fluctuations in their consultation rates were large (grey line) due to very few consultations for those features being recorded. Their underlying trends were only made obvious after smoothing (black line).

- The frequency of primary care consultations for convulsions or visual disturbance began to increase 12 months before brain tumour diagnosis (black line), at a point earlier than when the frequency of hospital admissions with those symptoms began to increase.

- The difference between the pattern of primary and secondary care visits for visual disturbance was more pronounced. Dysfunction of cranial nerve II, III, IV or VI was seen in primary care with increasing frequency 24 months before a brain tumour diagnosis, long before those patients began to present in hospitals 3-6 months before the definitive diagnosis of tumour. 
Chu TPC, Shah A, Walker D, Coleman MP. Pattern of symptoms and signs of primary intracranial tumours in children and young adults: a record linkage study. Arch Dis Child 2015.

http://dx.doi.org/10.1136/archdischild-2014-307578

Primary care:
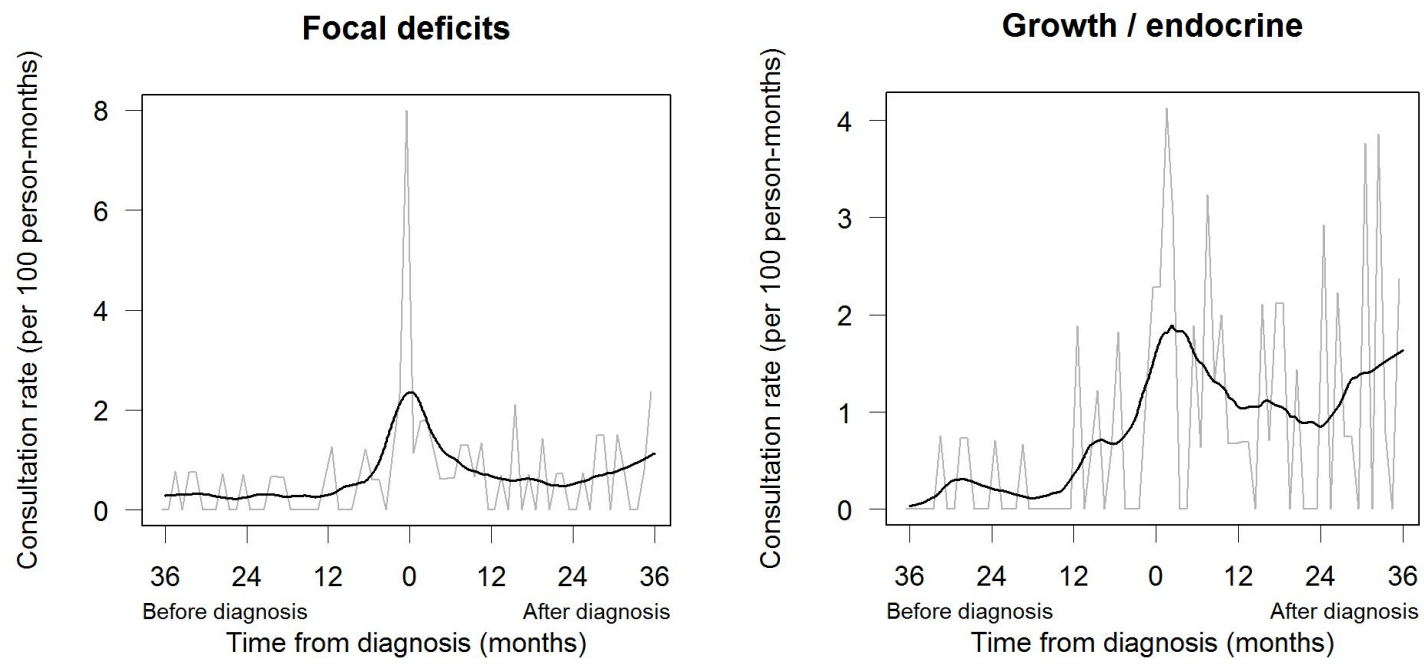

Secondary care:

Focal deficits

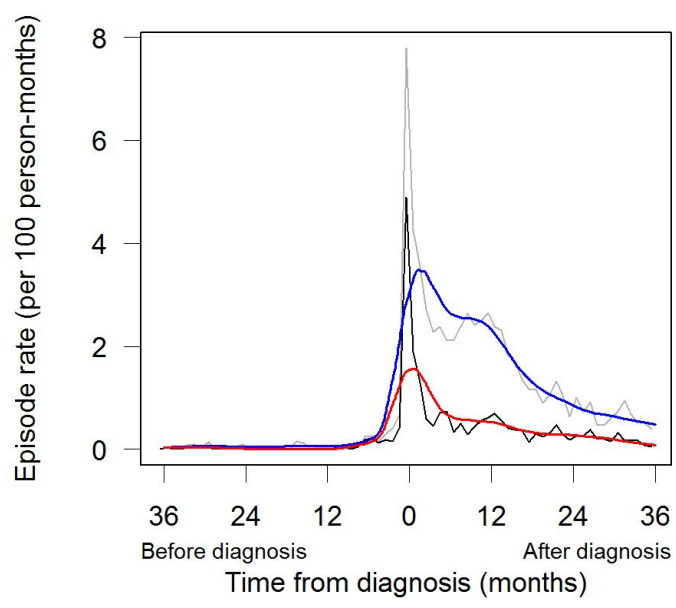

Growth / endocrine

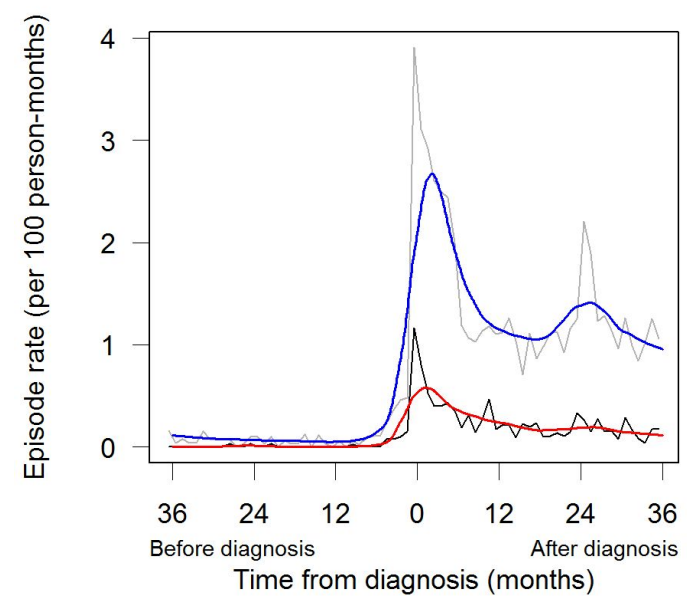

- Focal neurological deficits were uncommon in both primary and secondary care, until the last 3-6 months before the diagnosis of an intracranial tumour.

- Changes in the frequency of consultations for growth or endocrine disorders occurred much earlier in primary care (about 24 months before the intracranial tumour was diagnosed) than in hospitals (around six months before diagnosis). 
Chu TPC, Shah A, Walker D, Coleman MP. Pattern of symptoms and signs of primary intracranial tumours in children and young adults: a record linkage study. Arch Dis Child 2015.

http://dx.doi.org/10.1136/archdischild-2014-307578

Primary care:
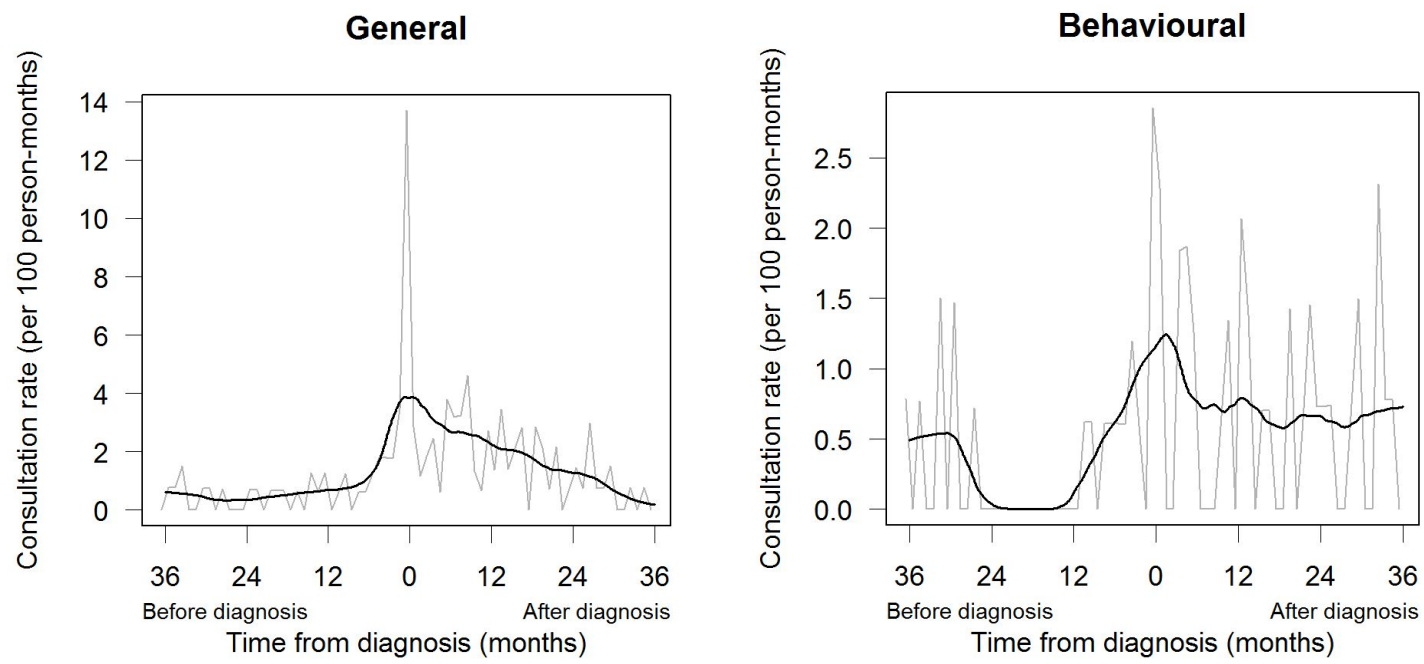

Secondary care:

General

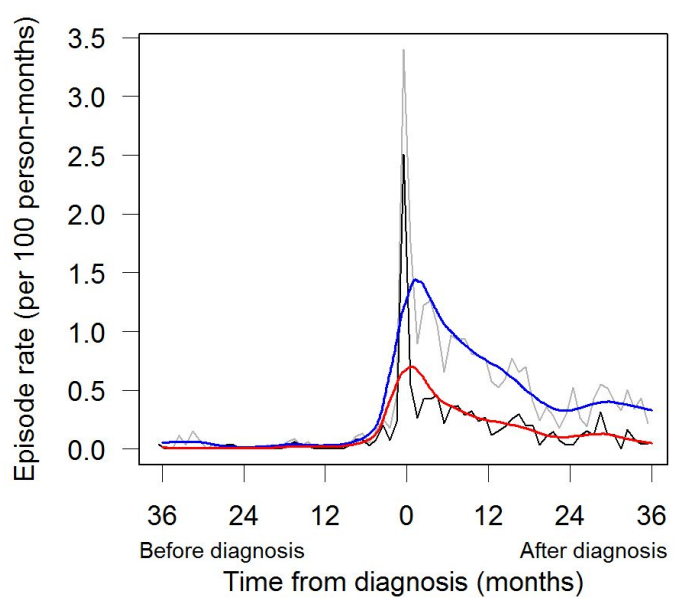

Behavioural

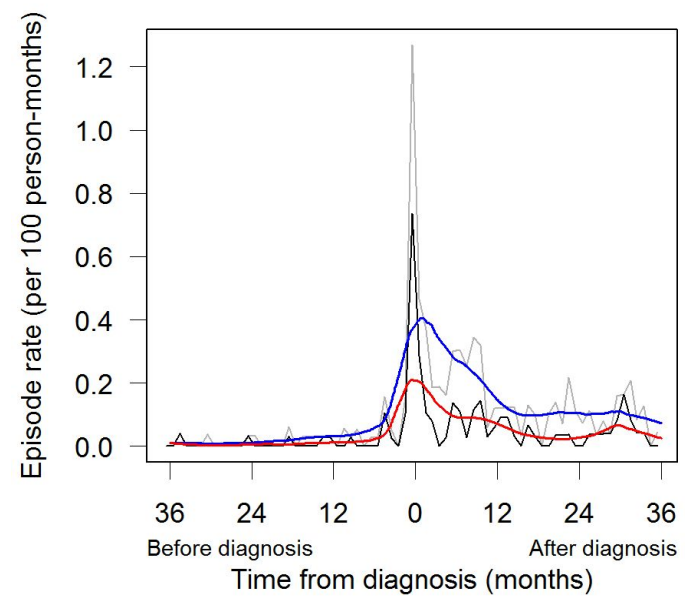

- Consultations in primary care for general or non-specific symptoms such as lethargy, appetite loss gradually increased in frequency 6-12 months before the brain tumour diagnosis. The rise in frequency became steeper from that time, with a corresponding increase in hospital admissions with those symptoms.

- Behavioural problems were uncommon. The increase in presentations was likely to be driven by an increase in the frequency at which other symptoms and signs occurred. 